\title{
Effect of Developmental Therapy on the Psychomotor Development in Preterm Infant
}

\author{
MD. JAVED IQBAL ${ }^{1}$, MD. MIZANUR RAHMAN² ${ }^{2}$ SHAHEEN AKHTER ${ }^{3}$
}

\begin{abstract}
Background: Preterm brain is prone to hypoxia and other insults that result in psychomotor delay. Early intervention in the form of developmental therapy in preterm babies reduces the subsequent psychomotor delay. A study was conducted to evaluate the psychomotor developmental outcome of preterm infant who got developmental therapy.

Objective: To evaluate the psychomotor developmental outcome of preterm infant who will be getting developmental therapy.

Methods: It was a quasi experimental study (single group pretest/post test design). It was carried out among the preterm babies who attended within 6-12 weeks of age for developmental assessment at the Centre for Neuro Development \& Autism in Children (CNAC) Bangabandhu Sheikh Mujib Medical University (BSMMU) during the period of July 2010 to September 2011. Forty five preterm infants were assessed for their motor, mental \& behavior score by Bayley Scale of Infant Development II, (BSID) (1993) Bengali version). All of them got Developmental therapy regularly as per demonstration in both home and Hospital. Their base line assessment was done at 6-12 weeks of age and reassessed at 3 months and 6 months after developmental therapy.
\end{abstract}

Results: Thirty seven (82.2\%) infants have completed the two follow up session. At 6 months of developmental therapy $54.1 \%$ had motor skill improvement, $40.5 \%$ had mental skill improvement and $48.6 \%$ had behavior skill improvement. Socio economic status and illness in neonatal period had some influence on developmental out come.

Conclusion: Developmental Therapy improved the psychomotor development in preterm infant.

Key Words: Developmental Therapy, Psychomotor Development, Preterm infant.

\section{Introduction}

Preterm babies are at risk of developmental problems due to several reason as reported by many studies. ${ }^{1,2}$ Early intervention programme in the form of developmental therapy are more suitable to promote growth and development of at risk preterm infants who are more vulnerable to growth and developmental faltering. ${ }^{3-5}$ Developmental therapy is the combination of various developmental stimulation like physical

1. Junior Consultant, Pediatrics, Upazila Health Complex, Hajiganj, Chandpur.

2. Professor of Pediatric Neurology, Department of Pediatrics, Bangabandhu Sheikh Mujib Medical, University, Dhaka.

3. Professor of Pediatric Neurology, Department of Pediatrics, Bangabandhu Sheikh Mujib Medical, University, Dhaka.

Correspondence: Dr. Md. Javed Iqbal, Junior Consultant Pediatrics, Upazila Health Complex, Hajiganj, Chandpur. E-mail: drmdjavediqbal@yahoo.com stimulation, cognitive stimulation and visual stimulation etc. A study showed the effect of a year long home intervention with a sample of preterm infants who got developmental intervention, a parent infant intervention and a no treatment control group. All infants were assessed regularly. The results suggests that developmental intervention approaches were more effective in improving the infants cognitive development. ${ }^{6.7}$

Many studies have observed the adverse sequelae of preterm birth and if intervention can be given at early stage it can improve and stimulate the developing brain of preterm infants. ${ }^{8}$ This prospective study was to observe the impact of developmental therapy in preterm babies in reducing subsequent impairment and disabilities. 


\section{Materials and methods}

This was a quasi experimental study (single group pretest/post test design) carried out in the Centre for Neurodevelopment and Autism in Children (CNAC). In the department of Paediatrics, Bangabandhu Sheikh Mujib Medical University. Babies who were born prematurely and came at 6-12 weeks of age for developmental assessment was included in the study period from July 2010 to September 2011. Sample size was 45 Preterm babies with out any congenital anomalies or any severe illness. At first visit assessment was done by investigator, developmental therapist and psychologist. Developmental therapy was given by trained developmental therapist in the form of tactile and kinesthetic stimulation, visual stimulation, cognitive stimulation. Mother or care giver were taught and advised to perform the therapy at home regularly. Feedback was taken from them whether they perform the therapy successfully at home during their successive visit. Their motor, mental and behavioral status was assessed by the principal investigator assisted by developmental psychologist at 3 months interval. Assessment was done according to Bayley Scales of Infant Development II (BSID-II), which consists of motor scale, mental scale, behavior rating scale. Improvement of outcome was assessed in the following manner-firstly the deviation between the observed scores of children at base line and reference median scores of normal children (obtained from BSID-II) of the same age were calculated. The deviations were then converted into percentage. Similarly, the percentage of deviation after 6 months of therapy was calculated with respect of normal children (obtained from BSID-II) of the same age. The percentage of deviation after 6 month of therapy was then substracted from that of the baseline and categorized as improved and not improved. A preformed semi structured data collecting form was used for data collection in each visit. It includes particulars of the patient, gestational age, birth weight, socio economic status, education of the parents, perinatal and neonatal history, past history, neonatal diagnosis and management. Motor, mental and behaviour scores were obtained from BSID-II.

\section{Results}

A total of 45 infants born preterm who attended the CNAC of BSMMU for development were enrolled. Of the 45 infants $37(82.2 \%)$ completed the two follow up session and hence were evaluated against their base line motor, mental and behavior score. Fig.-1 shows among the study subjects $57 \%$ were male and $43 \%$ were female. Among them $5 \%$ had the gestation period of $34-36$ weeks and $57 \%$ had gestation age of 28-30 weeks.

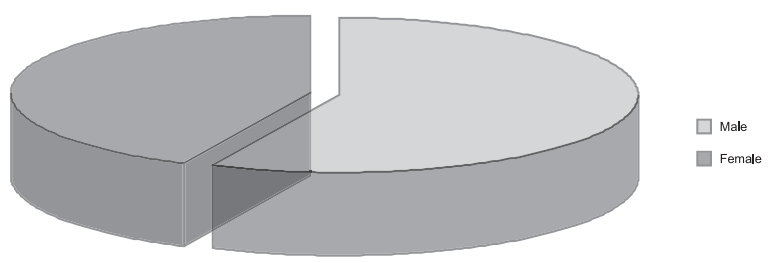

Fig-1: Pie chart shows sex distribution of the infants.

Fig.-2 Shows $67.6 \%$ of infants came from middle income group family, $18.9 \%$ from poor and the rest $13.5 \%$ from rich family.

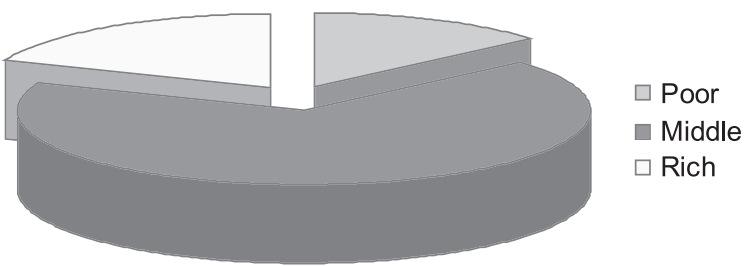

Fig-2: Pie diagram shows the socioeconomic status of the parents of the study infants.

Assessment of neonatal events demonstrate that $35.1 \%$ of the infant were suffering from jaundice, $27 \%$ had septicemia and perinatal asphyxia was present in $18.9 \%$ cases (Table-I).

Table-I

Distribution of the children by neonatal events $(n=37)$

\begin{tabular}{ccc}
\hline Neonatal events & Frequency & Percentage \\
\hline Jaundice & & \\
Present & 13 & 35.1 \\
Absent & 24 & 64.9 \\
Septicemia & & \\
Present & 10 & 27 \\
Absent & 27 & 73 \\
Perinatal asphyxia & & \\
Present & 7 & 18.9 \\
Absent & 30 & 81.1 \\
\hline
\end{tabular}

Baseline assessment of children revealed that motor score of $62.2 \%$ of children, mental score of $78.4 \%$ and behavior score of $62.9 \%$ children were below normal (table-II).

Table-II

Base line Assessment of motor mental \& behavior status of the study subjects $(n=37)$

\begin{tabular}{lcc}
\hline Base line assessment & Normal & Below Normal \\
\hline Motor status & $14(37.8 \%)$ & $23(62.2 \%)$ \\
Mental Status & $8(21.6 \%)$ & $29(78.4 \%)$ \\
Behavior status & $14(37.8 \%)$ & $23(62.9 \%)$ \\
\hline
\end{tabular}


Among the 37 infant motor skill improved of $36.8 \%$ at 3 months and $54.1 \%$ at 6 months, mental skill improved $28.94 \%$ at 3 months and $40.5 \%$ at 6 months. Behavioral skill improvement $34.2 \%$ at 3 months and $48.6 \%$ at 6 months (table-III). Different level of socio economic status of the family did not influence the motor function $(p=0.07)$ and behavior function improvement $(p=0.47)$ but it influences the mental function improvement $(p=0.01$ ) (Table-IV). Children who were suffering from jaundice in neonatal period showed only improvement in motor function $(p=0.03)$ but no improvement in mental function ( $p=0.37$ ) or behaviour function $(p=0.64)$ following developmental therapy. Both early and late sepsis had no influence on motor function, mental function and behavior function improvement following developmental therapy (Table-V).

Mothers level of education, (table-IV) feeding practice (Table-VI) had no impact on developmental out come following developmental therapy.

Table-III

Distribution of the children by developmental out come ( $n=37)$

\begin{tabular}{lccccc}
\hline Developmental out come & \multicolumn{2}{c}{ After 3 months } & & \multicolumn{2}{c}{ After 6 month } \\
\cline { 2 - 3 } \cline { 5 - 6 } & Frequency & Percentage & & Frequency & Percentage \\
\hline Motor function improved & 14 & 36.84 & & 20 & 54.1 \\
Mental function improved & 11 & 28.94 & & 15 & 40.5 \\
Behevioral function improved. & 13 & 34.21 & & 18 & 48.6 \\
\hline
\end{tabular}

Table-IV

Association between socioeconomic status and maternal educational status with developmental out come of study subjects $(n=37)$

\begin{tabular}{|c|c|c|c|c|c|c|}
\hline \multirow[t]{4}{*}{ Socio economic status } & \multicolumn{6}{|c|}{ Developmental out come } \\
\hline & \multicolumn{2}{|c|}{ Motor } & \multicolumn{2}{|c|}{ Mental } & \multicolumn{2}{|c|}{ Behavior } \\
\hline & Improved & Not & Improved & Not & Improved & Not \\
\hline & & Improved & & Improved & Improved & \\
\hline Poor & $57.1 \%$ & $42.9 \%$ & $42.9 \%$ & $57.1 \%$ & $28.6 \%$ & $71.4 \%$ \\
\hline Middle & $44 \%$ & $56 \%$ & $28 \%$ & $72 \%$ & $52 \%$ & $48 \%$ \\
\hline Rich & $100 \%$ & $0 \%$ & $100 \%$ & $0 \%$ & $60 \%$ & $40 \%$ \\
\hline P-Value & 0.07 & 0.01 & 0.47 & & & \\
\hline \multicolumn{7}{|l|}{ Mother educational status } \\
\hline Illiterate & 0 & $1(100.0)$ & $1(100.0)$ & 0 & 0 & $1(100.0)$ \\
\hline Literate & $13(52.0)$ & $12(48.0)$ & $8(32.0)$ & $17(68.0)$ & $11(44.0)$ & $14(56.0)$ \\
\hline Graduate & $7(63.3)$ & $4(36.7)$ & $6(54.5)$ & $5(45.5)$ & $7(63.3)$ & $4(36.7)$ \\
\hline p value & \multicolumn{2}{|c|}{044} & \multicolumn{2}{|c|}{0.21} & \multicolumn{2}{|c|}{0.34} \\
\hline
\end{tabular}


Table-V

Association between neonatal events and developmental outcome of the study infants ( $n=37$ )

\begin{tabular}{|c|c|c|c|c|c|c|}
\hline \multirow[t]{4}{*}{ Jaundice } & \multicolumn{6}{|c|}{ Developmental outcome } \\
\hline & \multicolumn{2}{|c|}{ Motor } & \multicolumn{2}{|c|}{ Mental } & \multicolumn{2}{|c|}{ Behavior } \\
\hline & Improved & Not & Improved & Not & Improved & Not \\
\hline & & Improved & & Improved & & Improved \\
\hline Present & $30.8 \%$ & $69.2 \%$ & $30.8 \%$ & $69.2 \%$ & $53.9 \%$ & $46.1 \%$ \\
\hline Absent & $66.7 \%$ & $33.3 \%$ & $45.8 \%$ & $54.2 \%$ & $45.8 \%$ & $54.2 \%$ \\
\hline P-Value & 0.03 & 0.37 & 0.64 & & & \\
\hline \multicolumn{7}{|c|}{ Septicemia } \\
\hline Present & $40 \%$ & $60 \%$ & $40 \%$ & $60 \%$ & $50 \%$ & $50 \%$ \\
\hline Absent & $59.2 \%$ & $40.8 \%$ & $40.8 \%$ & $59.2 \%$ & $48.1 \%$ & $51.9 \%$ \\
\hline P-Value & \multicolumn{2}{|c|}{0.29} & \multicolumn{2}{|c|}{1.0} & \multicolumn{2}{|c|}{0.92} \\
\hline
\end{tabular}

Table-VI

Association of feeding practice with developmental out come $(n=37)$

\begin{tabular}{|c|c|c|c|c|c|c|}
\hline \multirow[t]{3}{*}{ Feeding practice } & \multicolumn{6}{|c|}{ Development al outcome } \\
\hline & \multicolumn{2}{|c|}{ Motor } & \multicolumn{2}{|c|}{ Mental } & \multicolumn{2}{|c|}{ Behavior } \\
\hline & Improved & $\begin{array}{c}\text { Not } \\
\text { improved }\end{array}$ & Improved & $\begin{array}{c}\text { Not } \\
\text { improved }\end{array}$ & Improved & $\begin{array}{c}\text { Not } \\
\text { improved }\end{array}$ \\
\hline Breastfed exclusive & $7(58.3)$ & $5(41.7)$ & $5(41.7)$ & $7(58.3)$ & $8(66.7)$ & $4(33.3)$ \\
\hline Non breastfed & 13(52.0) & 12(40.0) & $10(40.0)$ & 15(60.0) & $10(40)$ & $15(60)$ \\
\hline p value & \multicolumn{2}{|c|}{0.13} & \multicolumn{2}{|c|}{0.92} & \multicolumn{2}{|c|}{0.13} \\
\hline
\end{tabular}

\section{Discussion}

In the present study after giving developmental therapy motor function was improved in $54.1 \%$ infant, mental function was improved in $40.5 \%$ infants and behavior function was improved in $48.6 \%$ infant. The Girolanic et al showed the improvement on motor out come in preterm infant following developmental therapy but no improvement in their behavior state. ${ }^{9}$ Lekskulchai and cole showed in a randomized control trial on 27 children that developmental intervention programme is likely to have a beneficial effect when offered to preterm infants. ${ }^{10}$

A study conducted by Mathai et al showed that tactile kinesthetic stimulation had a beneficial effect on growth and behavior development. ${ }^{6}$ It was shown that development was not improved in all domains simultaneously. It might be due to variation in the pattern of intervention and stimulus given to study subjects, like physical therapy improved the motor function ${ }^{9}$, home environment improve the cognitive development. ${ }^{7}$

Present study showed that maternal Educational status did not influence motor, mental and behavior function improvement. Khan et al $^{11}$ showed on 159 Bangladeshi preterm infant that maternal education influenced the developmental out come of preterm infants. ${ }^{11}$ Disparity of the results between the two studies might be due to smaller sample size in the present study.

This study showed that jaundice in the neonatal period had only improvement in motor outcome but no improvement in mental and behavior out come following developmental therapy examination. Graziani et al reported in a study that hyperbilirubinaemia in a range of 2.9-22.5 mg/dl was not the cause of developmental delay. ${ }^{12}$ It might be due to the wide range of serum bilirubin in that study.

In the present study it was not evident that sepsis could influence the motor, mental and behavior out 
come in preterm infants following developmental therapy. There is no such study in the past that could match with the present study. Present study showed that various feeding practice showed no variation in motor, mental and behavior out come following developmental therapy. But Morley showed that in 771 low birth weight infant whose mothers choose to provide breast milk had an 8 point advantage in mean Bayleys mental developmental index over infants of mother choosing not to do so. ${ }^{13}$ This differences is due to smaller sample size of the present study.

So from the above discussion, the present study support the hypothesis that developmental therapy is effective to improve psychomotor development in preterm infant.

\section{Conclusion}

The present Study observed that developmental therapy is effective to improve motor, mental and behavior function of a high number of preterm infants. The present study also found that socio economic status and neonatal jaundice had partial influence on developmental out come.

\section{Recommendation}

Developmental therapy should be started in preterm infant in their earliest possible time.

Further study should be with large sample size, long follow up period and observing various developmental aspects beside psychomotor development to see the effect of developmental therapy.

\section{Limitation of the study}

Small sample size.

Study period was short considering developmental out come.

Control group could not be taken.

Parental compliance and way of developmental therapy given at home could not be observed and was totally based on interview of the parents or caregiver.

\section{References}

1. Anneloes L, Barr V, Allied G, Wassenara V, Judy $M$, Friedo $W$, et al. Very preterm birth is associated with disabilities in multiple developmental domain. J of ped psycho. 2005; 30:247-55.
2. Richardson DK, Gray JE, Gortmaker SL, Goldman DA, Pursley DM, Mc Cormick MC. Declining Severity adjusted mortality: Evidence of improving neonatal intensive care. Pediatrics. 1998;102:898-99.

3. The state of the worlds children, UNICEF2001. New York and Oxford University press. Oxford UK.

4. Khan MR, Rahman ME. Essence of pediatrics. $3^{\text {rd }}$ ed Dhaka. Anwara Khan;2004.p.3-17.

5. Sturney P, Thorbern MJ, Brown JM, Reed J, King G. Protage guide to early intervention: crosse cultural aspects and intercultural variability. $\mathrm{J}$ of Child Care Health and Dev. 1992;18:377-94.

6. Mathai S, Fernendez A, Mondkar J, Karbi W. Effects of tactile kinesthetic stimulation: a controlled trial. Indian Pediatr. 2001;38:1091-97.

7. Barrera ME, Resenbaum PL, Cunningham CE. Early home intervention with low birth weight infants and their parents. Child development. 1986;57:20-33.

8. Deckleine MJK, Den Ouden Al, Kolle. Developmental evaluation and follow up assessment of preterm infants at 5 years of age. Arch of Dis of Child. 2004;88:870-75.

9. Girolani GL, Sujan K, Campbell PT. Efficacy of a neurodevelopmental treatment programme to improve motor control in infants born prematurely. Padiatr Phys ther. 1994;6:175-84.

10. Lekskulchai R, Cole J, Effects of developmental programme on motor performance in infants born preterm. Aus J of physiother. 2001;47:169-76.

11. Khan NZ, Muslima H, Parveen M, Bhottacharya M, Begum N, Chowdhury S. Neurodevelopmental out come of preterm infants in Bangladesh. Pediatrics. 2006;3:3-17.

12. Graziani LJ, Mitchel DG, Krnhauser M. Neurodevelopment of preterm infants, Neonatal neurosonographic and serum bilirubin studies. Pediatrics. 1992;89:229-34.

13. Morley R, Cole TJ, Powell R, Lucas A. Mothers choice to provide breast milk and developmental out come. Arch Dis Child. 1988;63:1382-85. 